\title{
Slit2-Robo1 signaling promotes the adhesion, invasion and migration of tongue carcinoma cells via upregulating matrix metalloproteinases 2 and 9, and downregulating E-cadherin
}

\author{
YUAN ZHAO ${ }^{1}$, FENG-LI ZHOU ${ }^{2}$, WEI-PING LI $^{3}$, JING WANG ${ }^{1}$ and LI-JING WANG ${ }^{4}$ \\ ${ }^{1}$ Department of Oral Basic Science, College of Stomatology, Lanzhou University, Lanzhou, Gansu 730000; \\ ${ }^{2}$ Department of Respiratory Medicine, The Third Affiliated Hospital of Sun Yat-sen University, Guangzhou, \\ Guangdong 510620; ${ }^{3}$ Department of Urology, Lanzhou General Hospital of Military Region, Lanzhou, Gansu 730000; \\ ${ }^{4}$ Vascular Biology Research Institute, Guangdong Pharmaceutical University, Guangzhou, Guangdong 510006, P.R. China
}

Received June 3, 2015; Accepted March 29, 2016

DOI: $10.3892 / \mathrm{mmr} .2016 .5518$

\begin{abstract}
Whether Slit homologue 2 (Slit2) inhibits or promotes tumor cell migration remains controversial, and the role of Slit2-Roundabout 1 (Robo1) signaling in oral cancer remains to be fully elucidated. The aim of the present study was to investigate the role of Slit2-Robo1 signaling in the adhesion, invasion and migration of tongue carcinoma cells, and the mechanism by which Slit2-Robol signaling inhibits or promotes tumor cell migration. Tca8113 tongue carcinoma cells were treated with the monoclonal anti-human Robol antibody, R5, to inhibit the Slit2-Robo1 signaling pathway, with immunoglobulin (Ig)G2b treatment as a negative control. The expression levels of Slit2 and Robo1 were determined using flow cytometry. The effects of R5 on the adhesion, invasion and migration of Tca8113 tongue carcinoma cells were investigated. Gelatin zymography was used to investigate the activity of matrix metalloproteinase 2 (MMP2) and MMP9. Western blot analysis was used to evaluate the expression levels of E-cadherin in Tca8113 cells treated with $10 \mu \mathrm{g} / \mathrm{ml}$ of either R5 or IgG2b. Slit2 and Robo1 proteins were found to be expressed in the Tca8113 cells. R5 significantly inhibited the adhesion, invasion and migration of Tca8113 cells in vitro. R5 also inhibited the activities of MMP2 and MMP9, and increased the expression of E-cadherin in the Tca8113 cells. These results suggested that Slit2-Robo1 signaling promoted the adhesion, invasion and migration of tongue carcinoma cells by upregulating the expression levels of MMP2 and MMP9 and, downregulating the expression of E-cadherin.
\end{abstract}

Correspondence to: Professor Li-Jing Wang, Vascular Biology Research Institute, Guangdong Pharmaceutical University, 280 Wai Huan Dong Road, Guangzhou, Guangdong 510006, P.R. China E-mail: wanglijing62@163.com

Key words: adhesion, cancer research, metastasis, tumor cell culture, tumor markers

\section{Introduction}

Slit is a chemorepellent in axon guidance and neuronal migration, and an inhibitor of leukocyte chemotaxis via the Roundabout (Robo) receptor. In mammals, the Slit family consists of three members: Slit homologue 1,2 and 3. Slit2 is widely expressed in various types of cancer in humans (1-3), and the interaction of Slit2 with Robo1 induces tumor angiogenesis (1). In addition, elevated expression levels of Slit2 in RIP1-Tag2 transgenic mice enhances tumor lymphangiogenesis and increases regional lymph node metastasis, indicating that Slit2 is also a regulator of adult lymphangiogenesis, and is a causal in Slit2-mediated lymphangiogenesis in the dissemination of tumor cells (4). In our previous study, R5, an anti-Robol monoclonal antibody, specifically inhibited the Slit2-Robol pathway to inhibit tumor growth and angiogenesis in human malignant melanoma A375 cells in mice and spontaneous tumors in a hamster cheek pouch carcinoma model $(1,5)$.

Oral tongue squamous cell carcinoma is the most common type of malignancy diagnosed in the oral and maxillofacial regions, and is characterized by a high degree of local invasiveness and a high rate of metastasis to cervical lymph nodes (6). A key step in the infiltration and metastasis of oral tongue carcinoma is the degradation of the basement membrane between the epithelium and lamina propria, around cancer nests and the surrounding vascular structures (7). High levels of proteases extending, even to the basement membrane, is a key stage in cancer invasion (8), as high levels of proteases facilitate degradation of the basement membrane and extracellular matrix (ECM), providing channels, which allow tumor cells to migrate and metastasize into the vascular and lymphatic systems (9). Furthermore, the invasiveness is associated with the ability of these proteases to degrade the basement membrane.

Matrix metalloproteinase 2 (MMP2) and MMP9 are gelatinases, which primarily degrade collagen IV (COL IV), the predominant component of the basement membrane and ECM, and that are also involved in neovascularization (10). As COL IV is widely distributed in tongue tissues, its physiological 
and pathological significance in oral tongue carcinoma has attracted increasing attention. Another molecule, E-cadherin, functions as a cell adhesion molecule in adherent junctions (11). The loss of E-cadherin leads to cell dissociation and the acquisition of a migratory phenotype during development, tissue remodeling or carcinogenesis $(12,13)$.

However, whether Slit2 inhibits or promotes tumor cell migration remains controversial, and the role of Slit2-Robo1 signaling in oral cancer remains to be fully elucidated. The aim of the present study was to investigate the role of Slit2-Robol signaling in the adhesion, invasion and migration of tongue carcinoma cells, and to determine the mechanism by which Slit2-Robo1 signaling inhibits or promotes tumor cell migration. The results suggested that Slit-Robo signaling is involved in the development of tongue carcinoma. The effectiveness of Slit-Robo signaling blockade in tongue carcinoma cells demonstrates a novel target for tongue cancer therapy.

\section{Materials and methods}

Reagents, antibodies and cell culture. Gelatin was purchased from Shanghai Shenggong Biological Co., Ltd. (Shanghai, China). Fibronectin (FN) was purchased from Sigma-Aldrich (St. Louis, MO, USA). The mouse anti-human Robol antibody, R5, (a Slit-Robo signaling-specific inhibitor), immunoglobuln (Ig)G2b control antibody and rabbit anti-human Slit2 and Robol antibodies were all donated by Dr. Geng Jianguo (University of Michigan, Ann Arbor, MI, USA). The Tca8113 cells (donated by Professor Wu Junzheng affiliated to The Forth Military Medical University, Xi'an, Shanxi, China) were cultured in RPMI 1640 medium (Invitrogen; Thermo Fisher Scientific, Inc., Waltham, MA, USA) supplemented with $10 \%$ fetal bovine serum (FBS; GE Healthcare Life Sciences, Logan, $\mathrm{UT}$, USA) at $37^{\circ} \mathrm{C}$ in $5 \% \mathrm{CO}_{2}$, and cells at the logarithmic growth phase were used in the subsequent experiments.

Flow cytometry. Flow cytometry was performed to detect the protein expression levels of Slit2 and Robol in the Tca8113 cells. The cells $\left(1 \times 10^{6}\right)$ were harvested and centrifuged at $188 \mathrm{x} \mathrm{g}$ at $25^{\circ} \mathrm{C}$ for $5 \mathrm{~min}$. Following centrifugation, the cells were resuspended in RPMI 1640. The cell suspensions (40 $\mu \mathrm{l}$ ) were incubated with $10 \mu \mathrm{g} / \mathrm{ml}$ mouse anti-human Slit2 antibody, rabbit anti-human Robo1 R5 antibody or IgG2b, and $10 \mu \mathrm{l}$ normal mouse or rabbit serum at room temperature for $20 \mathrm{~min}$. The cells were centrifuged at 1,000 rpm for $5 \mathrm{~min}$ and washed and resuspended in phosphate-buffered saline (PBS) containing $0.1 \% \mathrm{NaN}_{3}$ and $5 \%$ FBS. The resuspended cells were incubated with fluorescein isothiocyanate (FITC)-goat anti-mouse IgG (cat. no. BA101) or FITC-goat anti-rabbit IgG secondary antibodies (cat. no. A1105) (1:100; Boster Biological Engineering Co., Ltd., Wuhan, China) at room temperature for $1 \mathrm{~h}$, centrifuged at $188 \mathrm{x} \mathrm{g}$ for $5 \mathrm{~min}$, and washed and resuspended in PBS twice. Subsequently, 5,000 stained cells were analyzed using an ELITE ESP flow cytometer (Beckman Coulter, Carlsbad, CA, USA).

In vitro adhesion assay. The wells of 24-well plates were coated with $6.25 \mathrm{mg} / \mathrm{l}$ Matrigel (1 ml/well; BD Biosciences, San Jose, CA, USA) and incubated with RPMI 1640 media containing $1 \mathrm{~g} / \mathrm{l}$ bovine serum albumin (BSA; Beyotime
Institute of Biotechnology, Shanghai, China) at $37^{\circ} \mathrm{C}$ for $1 \mathrm{~h}$ to block nonspecific binding sites. The cells were collected, centrifuged at $188 \times \mathrm{g}$ for $5 \mathrm{~min}$, resuspended to $1 \times 10^{5}$ cells $/ \mathrm{ml}$ in RPMI 1640 media containing $0.1 \%$ BSA, and incubated at $37^{\circ} \mathrm{C}$ for $30 \mathrm{~min}$ to reconstitute surface proteins. Aliquots of $2 \times 10^{5}$ Tca8113 cells were seeded into individual Matrigel-coated wells and incubated at $37^{\circ} \mathrm{C}$ in $5 \% \mathrm{CO}_{2}$ for $60 \mathrm{~min}$. The wells were then gently washed three times with PBS, and the attached cells were harvested and counted using an Axio Observer A1/Axio Cam, PH (Carl Zeiss AG, Oberkochen, Germany). The experiment was performed in triplicate.

Cell migration assay. Briefly, 96-well tissue culture plates were coated with $50 \mu \mathrm{l}$ of $10 \mathrm{mg} / \mathrm{l} \mathrm{FN}$ overnight. The Tca8113 cells $\left(100 \mu \mathrm{l} ; 1 \times 10^{5} / \mathrm{ml}\right)$ in the logarithmic growth phase were seeded onto the 96-well plates and grown until confluent. The confluent cell monolayer was scratched with a probe, and the original medium was removed following scratching. The scratched plates were lightly washed with RPMI 1640 serum-free media. Then samples of media containing $1 \% \mathrm{FBS}$, $1 \% \mathrm{BSA}$, and $0.1,1.0$ or $10.0 \mu \mathrm{g} / \mathrm{ml} \mathrm{R} 5$ or $10 \mu \mathrm{g} / \mathrm{ml} \mathrm{IgG} 2 \mathrm{~b}$ were added to the 96 -well plates. The widths of the scratches were recorded immediately and following a $24 \mathrm{~h}$ period under an inverted microscope ( $\mathrm{PH}$, Axio Observer A1) at $37^{\circ} \mathrm{C}$. The distance of cell migration was determined as follows: Migration distance $=$ cell-free area at $0 \mathrm{~h}$ - cell-free area at $24 \mathrm{~h}$. The experiments were repeated three times.

Chemotaxis assay. A solution of $1 \times 10^{5} / \mathrm{ml}$ Tca8113 cells $(200 \mu 1$ free FBS and RPMI 1640 media) in the logarithmic growth phase were plated onto each Transwell chamber (BD Biosciences), following which $10.0 \mu \mathrm{g} / \mathrm{ml} \mathrm{R5}$ or IgG2b was added. The lower chambers were filled with $400 \mu 1$ RPMI 1640 media containing $0.1 \% \mathrm{BSA}$ and $16 \mu \mathrm{g} \mathrm{FN}$, which was used as a chemoattractant. After $24 \mathrm{~h}$ in continuous culture $37^{\circ} \mathrm{C}$, the Transwell chambers were removed, and the cells in the upper chambers were fixed with $95 \%$ ethanol, stained with Giemsa (Beyotime Institute of Biotechnology, Shanghai, China), and counted in 10 microscopic fields (magnification, x200) per chamber. Each assay was repeated in triplicate, and the invasion inhibitory rate was calculated as follows: Inhibitory rate $(\%)=(1-$ cells in R5-treated group / cells in IgG2b-treated group) x $100 \%$.

Gelatin zymography. The Tca8113 cells $\left(1 \times 10^{5}\right.$ cells $/ \mathrm{ml}$ in T-25 flasks) in the logarithmic growth phase were cultured for $24 \mathrm{~h}$. The medium was removed, and the cells were washed with serum-free RPMI 1640 medium. Subsequently, $3 \mathrm{ml}$ serum-free media containing $0.1,1.0$ or $10.0 \mu \mathrm{g} / \mathrm{ml} \mathrm{R} 5$ or $10.0 \mu \mathrm{g} / \mathrm{ml} \mathrm{IgG2b}$ was added to each flask. After $48 \mathrm{~h}$ of routine culture, the supernatants were collected and centrifuged at $3,000 \mathrm{x}$ g at room temperature for $10 \mathrm{~min}$. The clarified supernatants were concentrated using $10-\mathrm{KDa}$ molecular weight cut off Amicon Ultra Centrifugal Filter Units (EMD Millipore, Billerica, MA, USA) and quantified using a bicinchoninic acid protein assay kit (Pierce Biotechnology, Inc., Rockford, IL, USA). A total of $20 \mu \mathrm{g}$ protein was loaded onto a gelatin-containing gel $(8 \%$ acrylamide gel containing $1.5 \mathrm{mg} / \mathrm{ml}$ gelatin; Beyotime Institute of Biotechnology) and separated by electrophoresis. 
A

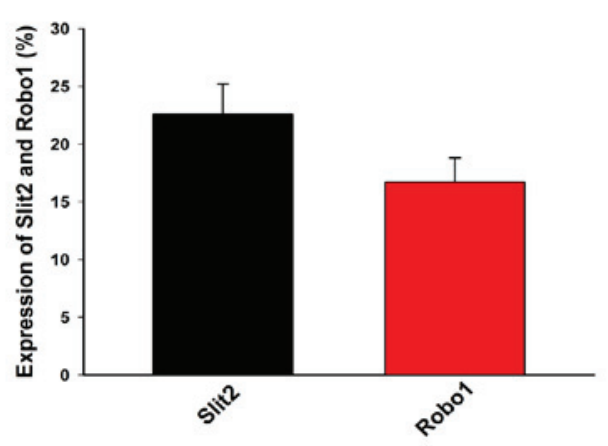

C

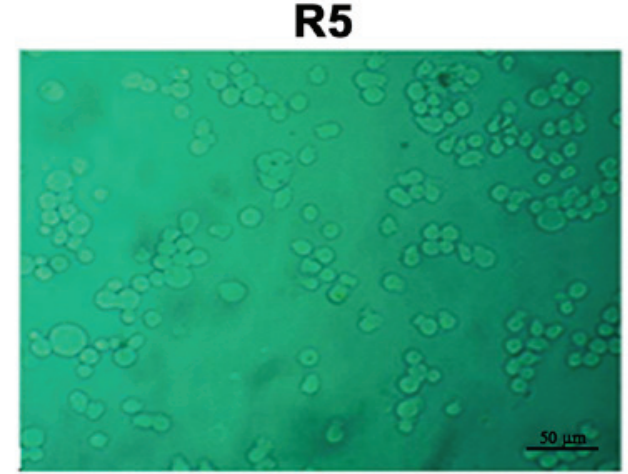

B
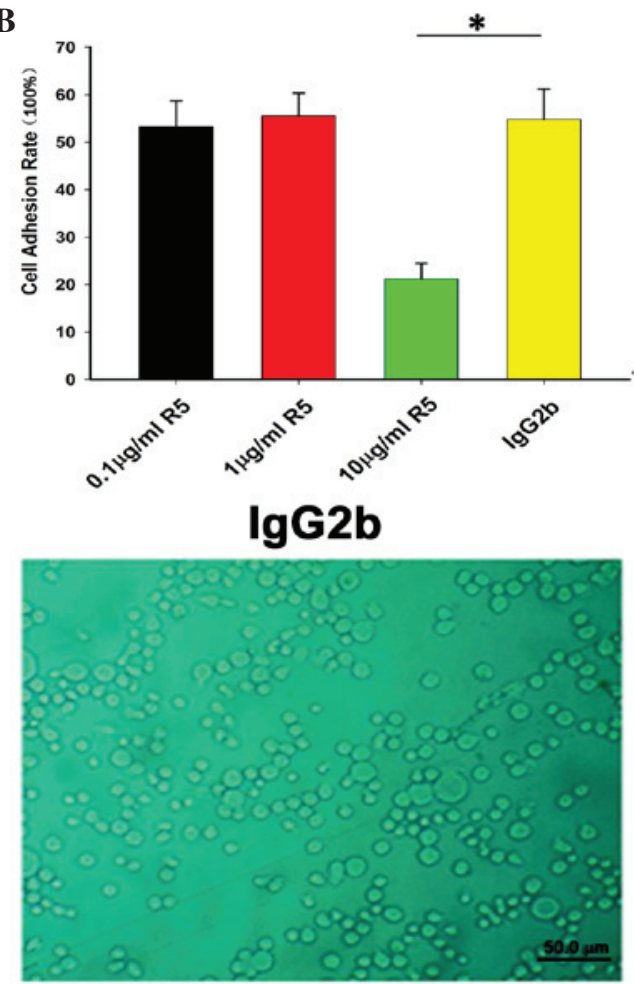

Figure 1. Effect of R5 treatment on Tca8113 cell adhesion to fibronectin. (A) Protein expression levels of Slit2 and Robo1 in the Tca8113 cells. (B) Attachment rates of the Tca8113 cells. (C) Representative images of Tca8113 cell adherence following treatment with $10 \mu \mathrm{g} / \mathrm{ml} \mathrm{R} 5 \mathrm{or} 10 \mu \mathrm{g} / \mathrm{ml} \mathrm{IgG} 2 \mathrm{~b}$ for $24 \mathrm{~h}$ (scale bar $=50 \mu \mathrm{m}$; magnification, x200). Data are expressed as the mean \pm standard deviation. *P<0.05. Slit 2 , Slit homologue 2; Robo1, Roundabout 1 ; IgG2b, immunoglobulin G2b.

Subsequently, the gel was washed with $2.5 \%$ Tween-20 solution (Sigma-Aldrich) in PBS (TPBS) and developed at $37^{\circ} \mathrm{C}$ in zymogram incubation buffer (Beyotime Institute of Biotechnology), containing $50 \mathrm{mM}$ Tris-HCL and $5 \mathrm{mM}$ $\mathrm{CaCl}_{2}$ (pH 7.6) overnight. Staining was then performed using $0.25 \%$ Coomassie blue R250 solution (Beyotime Institute of Biotechnology), and destained with 50\% methanol and $10 \%$ acetic acid (both from Sigma-Aldrich) until the membrane degraded by MMP2 or MMP9 became clear.

Western blotting. The Tca8113 cells were treated with $0.1,1.0$ or $10.0 \mu \mathrm{g} / \mathrm{ml} \mathrm{R} 5$, or were mock-treated with $10.0 \mu \mathrm{g} / \mathrm{ml} \mathrm{IgG} 2 \mathrm{~b}$, and routinely cultured for $48 \mathrm{~h}$. Subsequently, the cells were lysed with ice-cold lysis buffer (Cell Signaling Technology, Inc., Danvers, MA, USA), containing $50 \mathrm{mM}$ Tris- $\mathrm{HCl}$ (pH 7.6), $150 \mathrm{mM} \mathrm{NaCL}, 1 \mathrm{mM}$ DTT, $10 \mathrm{mM} \mathrm{NaF}$ and $2 \mathrm{mM} \mathrm{Na}_{3} \mathrm{VO}_{4}$, containing $0.1 \%$ sodium dodecyl sulfate (SDS) and $1 \mathrm{X}$ complete protease inhibitor cocktail (Sigma-Aldrich) for $30 \mathrm{~min}$. This was followed by centrifugation at $4^{\circ} \mathrm{C}$ and $13,800 \mathrm{x} \mathrm{g}$ for $15 \mathrm{~min}$. The total protein in the supernatant was determined using Bradford protein assay reagent (Bio-Rad Laboratories, Inc., Hercules, USA). Finally, $20 \mu \mathrm{g}$ of the cell extracts were separated by $12 \%$ SDS-polyacrylamide gel electrophoresis (PAGE) and transferred onto nitrocellulose membranes (GE Healthcare Life Sciences), which were blocked with 5\% skim milk/TPBS (0.1\% Tween-20) for $3 \mathrm{~h}$ and incubated with rabbit anti-human E-cadherin (1:1,000; cat. no. BA0474) or mouse anti-rabbit actin (cat. no. BM0627) (1:200; Boster Biological Engineering Co., Ltd.) at $25^{\circ} \mathrm{C}$ for $1 \mathrm{~h}$. The membrane was washed with Tris-buffered saline (Sigma-Aldrich) twice, each for $15 \mathrm{~min}$, incubated $\left(25^{\circ} \mathrm{C}\right.$ for $\left.1 \mathrm{~h}\right)$ with horseradish peroxidase-conjugated goat anti-rabbit and goat anti-mouse secondary antibodies (cat. nos. BA1055 and BA1051; Boster Biological Engineering Co., Ltd.), and developed using ECL Plus chemiluminescent reagents (GE Healtcare Life Sciences, USA). The relative intensities of the E-cadherin-specific bands of the R5-treated samples were digitalized and compared with those of the mock-treated samples using Quantity One software 4.6.2 (Bio-Rad Laboratories, Inc.), with $\beta$-actin used as a loading control.

Statistical analysis. The data were analyzed using Student's t-test and a $\chi^{2}$ test, using a computer-based SPSS 13.0 software program (SPSS, Inc., Chicago, IL, USA). The results are expressed as the mean \pm standard deviation. For all analyses, $\mathrm{P}<0.05$ was considered to indicate a statistically significant difference.

\section{Results}

Protein expression levels of Slit2 and Robol in Tca8113 cells. Flow cytometry was used to detect and quantify the intracellular protein expression levels of Slit2 and Robol. The percentages of Slit2-positive and Robo1-positive cells were $22.6 \pm 2.6$ and $16.7 \pm 2.1 \%$, respectively. These results demonstrated that Slit2 and Robol were expressed in the Tca8113 cells (Fig. 1A).

Effect of R5 on Tca8113 cell attachment to FN. The present study found that R5 inhibited the attachment of Tca8113 cells 
A
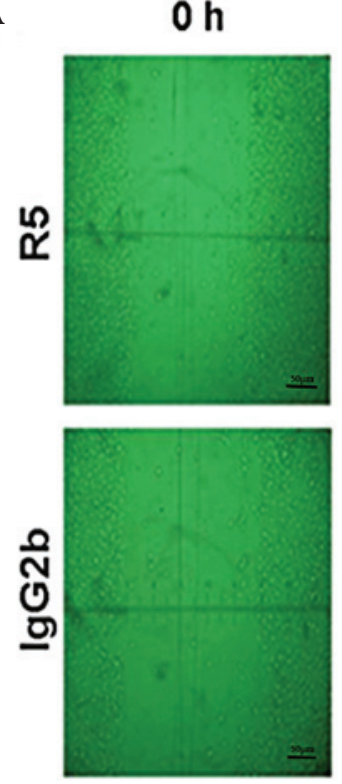

$24 \mathrm{~h}$
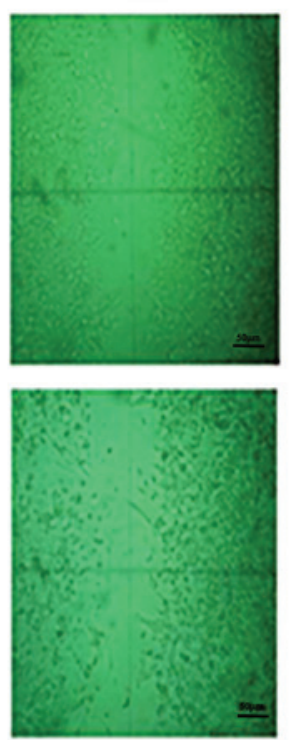

B

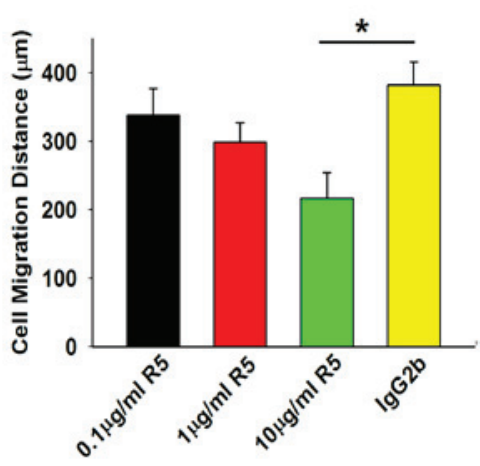

Figure 2. R5 inhibits Tca8113 cell migration. (A) Representative images of Tca8113 cell migration following treatment with $10.0 \mu \mathrm{g} / \mathrm{ml}$ R5 or IgG2b, showing the widths of the scratches (scale bar $=50 \mu \mathrm{m}$; magnification, $\mathrm{x} 100$ ). (B) Tca8113 cell migration distances. Data are expressed as the mean \pm standard deviation. ${ }^{*} \mathrm{P}<0.05$, based on Student's t-test. IgG2b, immunoglobulin G2b.

to FN. The attachment rate of the Tca8113 cells treated with $10.0 \mu \mathrm{g} / \mathrm{ml} \mathrm{R} 5(21.2 \pm 3.3 \%)$ was significantly lower, compared with that of the mock-treated Tca8113 cells $(54.8 \pm 6.4 \%$; $\mathrm{P}<0.05$; Fig. 1).

Effect of $R 5$ on Tca8113 cell migration. An in vitro scratch assay was used to investigate the migration of the cancer cells on the artificial basement membrane, Matrigel. The Tca8113 cells were either treated with R5 at different concentrations or were mock-treated with IgG2b, and allowed to grow for $24 \mathrm{~h}$ under routine conditions, followed by the introduction of a scratch to the cell monolayer. The migration distance of the Tca8113 cells treated with $10.0 \mu \mathrm{g} / \mathrm{ml} \mathrm{R} 5(217 \pm 37 \mu \mathrm{m})$ was significantly lower, compared with that of the mock-treated Tca8113 cells $(382 \pm 34 \mu \mathrm{m} ; \mathrm{P}<0.05$; Fig. 2$)$. The migration distances of the Tca8113 cells treated with $10.0 \mu \mathrm{g} / \mathrm{ml} \mathrm{R} 5$ were significantly lower, compared with those of the IgG2b-treated group.

Effect of $R 5$ on the chemotaxis of Tca8113 cells. The recovery of the scratched area in the Transwell chambers was examined to assess the chemotaxis of the Tca8113 cells treated with $10.0 \mu \mathrm{g} / \mathrm{ml} \mathrm{R} 5$ or IgG2b. The invasion inhibitory rate of the R5-treated Tca8113 cells $(24.67 \pm 0.03 \%)$ was significantly lower, compared with that of the mock-treated Tca8113 cells (33.21 $\pm 0.07 \%$; $\mathrm{P}<0.05$; Fig. 3).

R5 increases the activities of MMP2 and MMP9 in Tca8113 cells. The supernatants of the Tca8113 cells, following treatment with $0.1,1.0$ or $10.0 \mu \mathrm{g} / \mathrm{ml} \mathrm{R} 5$ or mock treatment with $10.0 \mu \mathrm{g} / \mathrm{ml} \mathrm{IgG} 2 \mathrm{~b}$, were analyzed using gelatin-incorporated SDS-PAGE to examine the activities of MMP2 and MMP9 in the cultured tumor cells. The results showed that treatment with $0.1,1.0$ or $10.0 \mu \mathrm{g} / \mathrm{ml} \mathrm{R} 5$ significantly inhibited the activities of MMP2 (72 KDa) and MMP9 (92 KDa) in the Tca8113 cells (Fig. 4).

Effect of $R 5$ on the expression of E-cadherin in Tca8113 cells. The Tca 8113 cells were treated with $0.1,1$, or $10.0 \mu \mathrm{g} / \mathrm{ml} \mathrm{R} 5$, or mock-treated with $10.0 \mu \mathrm{g} / \mathrm{ml} \mathrm{IgG} 2 \mathrm{~b}$, and routinely cultured for another $48 \mathrm{~h}$. The results of the western blotting showed that the expression of E-cadherin in the Tca8113 cells treated with R5 was significantly higher, compared with that in the mock-treated Tca8113 cells $(\mathrm{P}<0.05$; Fig. 4).

\section{Discussion}

The present study aimed to investigate the role of Slit2-Robo1 signaling in the adhesion, invasion and migration of tongue carcinoma cells, and examine the mechanism by which Slit2-Robo1 signaling inhibits or promotes tongue carcinoma cell migration. The monoclonal anti-Robol antibody, R5, was used to inhibit Slit2-Robol signaling, following which changes in cell invasion and migration, as well as the expression levels of MMP2, MMP9 and E-cadherin were examined in Tca8113 tongue carcinoma cells. It was found that R5 inhibited cell adhesion, invasion and migration and significantly reduced the expression levels of Slit2, Robo1, MMP2 and MMP9 in the Tca8113 cells, but increased the expression of E-cadherin.

The present study also found that R5 significantly inhibited the ability of the Tca8113 cells to attach to FN and invade the scratched area in vitro, compared with the mock-treated tongue carcinoma cells, indicating that R5 was capable of inhibiting the adhesion of the cancerous cells to the ECM. Of note, adhesion is important in cancer cell invasion and migration, as adhesion is the initiating step in cancer cell invasion, which includes a series of adhesion and de-adhesion processes 

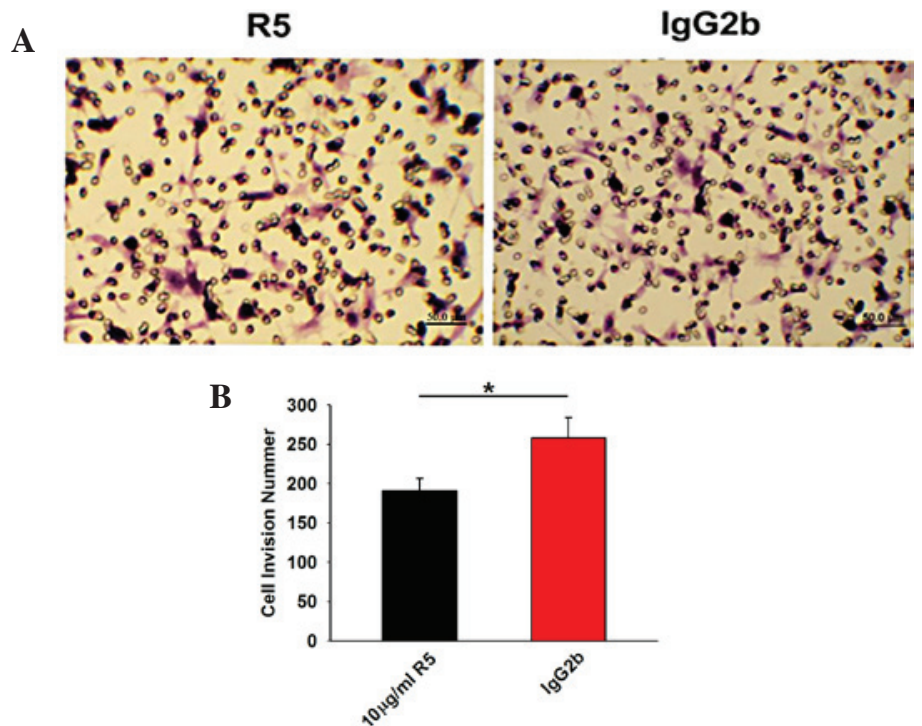

Figure 3. R5 inhibits Tca8113 cell invasion. (A) Representative images of Tca8113 cells treated with $10.0 \mu \mathrm{g} / \mathrm{ml} \mathrm{R} 5$ or IgG2b for $24 \mathrm{~h}$ and analyzed using invasion assays (scale bar $=50 \mu \mathrm{m}$ ). (B) Number of invading Tca8113 cells. Data are expressed as the mean \pm standard deviation. "P<0.05, based on Student's t-test. IgG2b, immunoglobulin G2b.

A

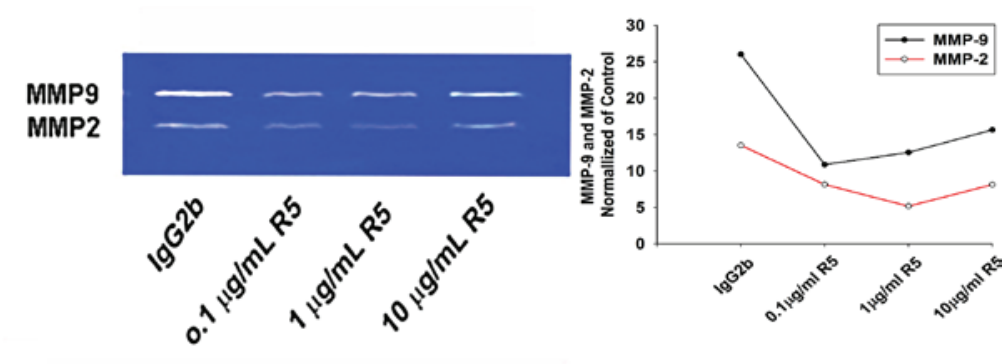

$\mathbf{B}$

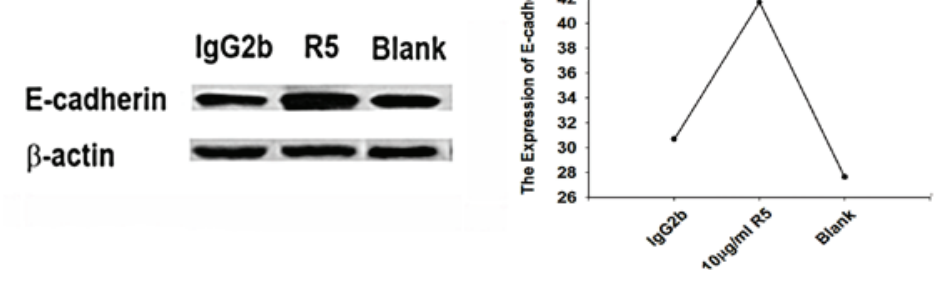

Figure 4. R5 inhibits Tca8113 cell invasion and migration by upregulating E-cadherin, and downregulating MMP2 and MMP9 in Tca8113 cells. (A) Gelatin zymography results showing that the expression levels of MMP2 and MMP9 in Tca8113 cells treated with $0.1,1.0$ or $10.0 \mu \mathrm{g} / \mathrm{ml}$ R5 were lower, compared

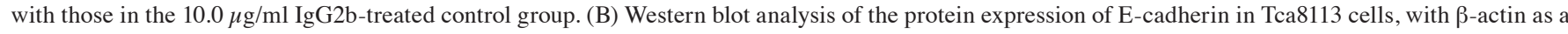
loading control. MMP, matrix metalloproteinase; IgG2b, immunoglobulin G2b.

involving certain ECM and basement membrane components, including FN. Cancer cells secrete degrading enzymes, including MMP2 and MMP3, to degrade the matrix following adherence to the matrix, leading to cancer cell migration into the area via chemotaxis (14).

The present study found that R5 significantly inhibited Tca8113 cell chemotaxis and migration on the FN-coated matrix in vitro. In addition to the ability to adhere to certain matrix components, active cell migration is an important activity in tumor invasion and metastasis. Cancer cells with high levels of invasiveness often also exhibit high levels of movement. Components of the ECM, including FN and certain growth factors in the ECM exert a chemotactic induction effect on tumor cell directional migration. For example, Slit2 has been shown to be associated with angiogenesis, which is important in cancer metastasis (15).

To delineate the mechanism of Slit2-Robo1-induced migration in the tongue cancer cells, the enzyme activities of MMP2 and MMP9 were examined using a substrate-specific gelatin-zymography assay. The resulting data indicated that the activities of MMP2 and MMP9 were significantly decreased in the Tca8113 cells treated with $\mathrm{R} 5$ for $48 \mathrm{~h}$ in vitro, with more pronounced inhibition of MMP9 activity, suggesting that inhibiting Slit2-Robo1 signaling upregulated MMP2 and MMP9. MMPs are a class of proteolytic enzymes, which are closely associated with tumor invasion and metastasis. Among all MMPs, MMP2 and MMP9 are the most important types for protease hydrolysis in the degradation of ECM, particularly 
COL IV in the cell basement membrane, and are important in cancer cell invasion and metastasis $(14,15)$.

The present study found that R5 significantly increased the protein expression of E-cadherin in the Tca8113 cells, as shown by western blot analysis, indicating that inhibiting Slit2-Robol signaling upregulated the expression of E-cadherin. E-cadherin is a critical adhesion molecule, and its downregulation or dysfunction causes cancer cells to lose the ability to adhere to each other and to migrate to regional lymph nodes or other remote sites (16). The knockdown of endogenous Robol or the specific inhibition of Slit2 binding to Robo1 prevents E-cadherin degradation and reverses the epithelial-mesenchymal transition, resulting in reduced tumor growth and liver metastasis (17).

In conclusion, the results of the current study have established that Slit-Robo signaling is important in adhesion, invasion and migration of tongue carcinoma cells. These results suggested that Slit2-Robol signaling promoted the adhesion, invasion and migration of tongue carcinoma cells by upregulating the expression levels of MMP2 and MMP9, and downregulating the expression of E-cadherin. Slit-Robo signaling may therefore be a novel target for tongue cancer therapy.

\section{Acknowledgements}

The present study was supported by the Fundamental Research Funds for the Central Universities, China (grant no. 1007RJYA009); the LanZhou University Ji Ben Ke Yan (lzujbky-2015-36 and lzujbky-2015-290); and the National Natural Science Foundation of China (grant no. 81500835).

\section{References}

1. Wang B, Xiao Y, Ding BB, Zhang N, Yuan Xb, Gui L, Qian KX, Duan S, Chen Z, Rao Y and Geng JG: Induction of tumor angiogenesis by Slit-Robo signaling and inhibition of cancer growth by blocking Robo activity. Cancer Cell 4: 19-29, 2003.

2. Dai CF, Jiang YZ, Li Y, Wang K, Liu PS, Patankar MS and Zheng J: Expression and roles of Slit/Robo in human ovarian cancer. Histochem Cell Biol 135: 475-485, 2011.
3. Li Y, Cheng H, Xu W, Tian X, Li X and Zhu C: Expression of Robo protein in bladder cancer tissues and its effect on the growth of cancer cells by blocking Robo protein. Int J Clin Exp Pathol 8: 9932-9940, 2015.

4. Yang XM, Han HX, Sui F, Dai YM, Chen M and Geng JG: Slit-Robo signaling mediates lymphangiogenesis and promotes tumor lymphatic metastasis. Biochem Biophys Res Commun 396: 571-577, 2010.

5. Wang LJ, Zhao Y, Han B, Ma YG, Zhang J, Yang DM, Mao JW, Tang FT, Li WD, Yang Y, et al: Targeting Slit-Roundabout signaling inhibits tumor angiogenesis in chemical-induced squamous cell carcinogenesis. Cancer Sci 99: 510-517, 2008.

6. Byers RM, El-Naggar AK, Lee YY, Rao B, Fornage B, Terry NH, Sample D, Hankins P, Smith TL and Wolf PJ: Can we detect or predict the presence of occult nodal metastases in patients with squamous carcinoma of the oral tongue? Head Neck 20: 138-144, 1998.

7. Garamszegi N, Garamszegi SP, Samavarchi-Tehrani P, Walford E, Schneiderbauer MM, Wrana JL and Scully SP: Extracellular matrix-induced transforming growth factor-beta receptor signaling dynamics. Oncogene 29: 2368-2380, 2012.

8. Rowe RG and Weiss SJ: Breaching the basement membrane: Who, when and how? Trends Cell Biol 18: 560-574, 2008.

9. Duffy MJ, McGowan PM and Gallagher WM: Cancer invasion and metastasis: Changing views. J Pathol 214: 283-293, 2008

10. Liotta LA, Steeg PS and Stetler-Stevenson WG: Cancer metastasis and angiogenesis: An imbalance of positive and negative regulation. Cell 64: 327-336, 1991.

11. Thiery JP and Sleeman JP: Complex networks orchestrate epithelial-mesenchymal transitions. Nat Rev Mol Cell Biol 7: 131-142, 2006

12. Shen Y, Hirsch DS, Sasiela CA and Wu WJ: Cdc42 regulates E-cadherin ubiquitination and degradation through an epidermal grow th factor receptor to Src-mediated pathway. J Biol Chem 283: 5127-5137, 2008

13. Weng W, Yin J,Zhang Y, Qiu J and Wang X: Metastasis-associated protein 1 promotes tumor invasion by downregulation of E-cadherin. Int J Oncol 44: 812-818, 2014

14. Westermarck J and Kähäri VM: Regulation of matrix metalloproteinase expression in tumor invasion. FASEB J 13: 781-792, 1999.

15. Guo SW, Zheng Y,Lu Y, Liu X and Geng JG: Slit2 overexpression results in increased microvessel density and lesion size in mice with induced endometriosis. Reprod Sci 20: 285-298, 2013.

16. Masterson J and O'Dea S: Posttranslational truncation of E-cadherin and significance for tumour progression. Cells Tissues Organs 185: 175-179, 2007.

17. Zhou WJ, Geng ZH, Chi S, Zhang W, Niu XF, Lan SJ, Ma L, Yang X, Wang LJ, Ding YQ and Geng JG: Slit-Robo signaling induces malignant transformation through Hakai-mediated E-cadherin degradation during colorectal epithelial cell carcinogenesis. Cell Res 21: 609-626, 2011. 